\title{
New improved method for fructooligosaccharides production by Aureobasidium pullulans
}

\author{
Ana Dominguez ${ }^{\mathrm{a}, *}$, Clarisse Nobre ${ }^{\mathrm{a}}$, Lígia R. Rodrigues ${ }^{\mathrm{a}, \mathrm{b}}$, António M. Peres $^{\mathrm{c}}$, Duarte Torres ${ }^{\mathrm{a}, \mathrm{b}}$, \\ Isabel Rocha ${ }^{a, b}$, Nelson Lima ${ }^{a}$, José Teixeira ${ }^{a}$ \\ a IBB - Institute for Biotechnology and Bioengineering, Centre of Biological Engineering, Campus de Gualtar, 4710-057 Braga, Portugal \\ b Biotempo - Consultoria em Biotecnologia, Lda., Avepark - Edifício Spinpark, Zona Industrial da Gandra, Barco, 4805-017 Guimarães, Portugal \\ ${ }^{\mathrm{c}}$ LSRE - Laboratory of Separation and Reaction Engineering - Associate Laboratory LSRE/LCM, Escola Superior Agrária, Instituto Politécnico de Bragança, \\ Quinta de Santa Apolónia, Apartado 172, 5301-855 Bragança, Portugal
}

\section{A R T I C L E I N F O}

\section{Article history:}

Received 22 September 2011

Received in revised form 26 March 2012

Accepted 29 March 2012

Available online 10 April 2012

\section{Keywords:}

Fructooligosaccharides

Aureobasidium pullulans

Transfructosylation

One-stage fermentation process

Response surface methodology

Product yield

\begin{abstract}
A B S T R A C T
Fructooligosaccharides are prebiotics with numerous health benefits within which the improvement of gut microbiota balance can be highlighted, playing a key role in individual health. In this study, an integrated one-stage method for FOS production via sucrose fermentation by Aureobasidium pullulans was developed and optimized using experimental design tools. Optimization of temperature and agitation speed for maximizing the FOS production was performed using response surface methodology. Temperature was found to be the most significant parameter. The optimum fermentation conditions were found to be $32^{\circ} \mathrm{C}$ and $385 \mathrm{rpm}$. Under these conditions, the model predicted a total FOS production yield of $64.7 \mathrm{~g}_{\text {Fos }} / \mathrm{g}_{\text {sucrose }}$. The model was validated at optimal conditions in order to check its adequacy and accuracy and an experimental yield of $64.1( \pm 0.0) \mathrm{g}_{\text {Fos }} / \mathrm{g}_{\text {sucrose }}$ was obtained. A significant improvement of the total FOS production yields by $A$. pullulans using a one-stage process was obtained.
\end{abstract}

(c) 2012 Elsevier Ltd. All rights reserved.

\section{Introduction}

Currently, it is widely recognised that the commensal bacterial community of human intestinal tract has a great impact on the gastrointestinal function, and consequently on human health and well-being (Gibson, Probert, Van Loo, Rastall, \& Roberfroid, 2004). Under this scope, in the recent years consumers have been increasingly confronted with the so-called functional food products among which probiotics and prebiotics constitute the most popular examples (De Preter, Hamer, Windey, \& Verbeke, 2011). According to the current definition of the United Nations' Food and Agriculture Organization (FAO), a prebiotic is a non-viable food component that confers a health benefit on the host associated with modulation of the microbiota (Playne \& Crittenden, 2004; Roberfroid, 2007).

Prebiotics are normally restricted to certain carbohydrates, particularly oligosaccharides, such as fructooligosaccharides (FOS), inulin, galactooligosaccharides, xylooligosaccharides,

Abbreviations: ANOVA, analysis of variance; FAO, food and agriculture organization; FOS, fructooligosaccharides; HPLC, high-performance liquid chromatography; MRLM, multiple linear regression model; SPSS, statistical package for social sciences; $\mathrm{VIF}$, variance inflation factor.

* Corresponding author. Tel.: +351 253604 400; fax: +351253604429.

E-mail address: anadominguezmatos@gmail.com (A. Dominguez). soybean oligosaccharides and isomaltooligosaccharides (Aachary \& Prapulla, 2011; Gibson et al., 2004; Sangeetha, Ramesh, \& Prapulla, 2005a; Torres, Gonçalves, Teixeira, \& Rodrigues, 2010). Several health benefits have been suggested for FOS. Besides being calorie-free and non-carcinogenic sweeteners, FOS have superior functional properties such as modulation of colonic microflora, improvement of the gastrointestinal physiology and immune functions, bioavailability of minerals, metabolism of lipids and prevention of colonic carcinogenesis (Biedrzycka \& Bielecka, 2004; Bornet, Brounsl, Tashiro, \& Duvillier, 2002; Qiang, YongLie, \& QianBing, 2009; Tanriseven \& Aslan, 2005).

FOS can be produced by the action of enzymes with transfructosylation activity (i.e. fructosyltransferase (EC 2.4.1.9) and/or $\beta$-fructofuranosidase (EC 3.2.1.26)) derived from plants and microorganisms. Most of these enzymes have been found in fungi such as Aureobasidium spp., Aspergillus spp., Penicillium spp. and Fusarium spp. (Dominguez, Santos, Teixeira, \& Lima, 2006; Mussatto, Aguilar, Rodrigues, \& Teixeira, 2009a; Yun, 1996; Prata, Mussatto, Rodrigues, \& Teixeira, 2010; Sangeetha, Ramesh, \& Prapulla, 2004). As an example, Yoshikawa, Amachi, Shinoyama, \& Fujii, 2006 reported that at least five $\beta$-fructofuranosidase are produced by Aureobasidium pullulans DSM2404 and three of them show a high transfructosylation activity.

Conventionally, FOS production is a two-stage process, in which the first stage consists in the microbial production of the enzyme 
with transfructosylation activity, and the second stage consists in the reaction of the extracted enzyme with sucrose (substrate) to produce FOS under controlled conditions (Mussatto, Aguilar, Rodrigues, \& Teixeira, 2009b; Sangeetha, Ramesh, \& Prapulla, 2005b). FOS production by fungi using bioreactors in a one-stage process is a great opportunity, as using whole cells as biocatalysts, either immobilized or free, eliminates the step of FOS-producing enzyme purification from the cell extracts (Chien, Lee, \& Lin, 2001; Mussatto et al., 2009a; Sangeetha et al., 2005a). Nevertheless, maximization of FOS yields can be affected by several factors that are involved in the whole process (one-stage process). The classical method of optimization involves changing one variable at a time, keeping the others at fixed levels. Being single dimensional, this laborious and time consuming method often does not guarantee determination of optimal conditions, neither takes into account possible interactions among various operational factors. Experimental design and optimization are tools that enable building models and evaluating the significance of the different factors considered, as well as their interactions. Furthermore, with these models, a small number of experimental trials are used to search the optimal factor levels that conduct to the desired response (Lundstedt et al., 1998; Montgomery, 1997).

Therefore, the aim of this work is to optimize the operation parameters, namely temperature and agitation speed, that maximize the total FOS production, using a $2^{k}$ full-factorial central composite experimental design. According to the factorial design, $2^{2}$ experiments plus 3 central points were performed. Additionally, 4 other points were also included in the set of experiments to make the central composite design rotatable, setting the distance from the central design equal to the square root of 2 .

\section{Materials and methods}

\subsection{Chemicals}

All chemicals used were of analytical grade. The FOS standards, 1-kestose, nystose and $1^{\mathrm{F}}$-fructofuranosylnystose, were purchased from Wako (Wako Pure Chemical Industries, Ltd., Japan).

\subsection{Microorganism and culture conditions}

The fungus A. pullulans is a fungus-like yeast, therefore it cannot be grown in liquid media from spores. The fungus was stored at $-20^{\circ} \mathrm{C}$ in liquid medium with glycerol $(17 \%, \mathrm{v} / \mathrm{v}$, pre-inoculum) after the following procedure: five discs of mycelium ( $8 \mathrm{~mm}$ diameter) were cut from the edge of the colony of $A$. pullulans kept in Czapek Dox Media (Oxoid, UK) plates (Fig. 1) and grown for 5 days at $28^{\circ} \mathrm{C}$ and $140 \mathrm{rpm}$ in inoculation medium containing sucrose $\left(100 \mathrm{~g} \mathrm{~L}^{-1}\right), \mathrm{NaNO}_{3}\left(10 \mathrm{~g} \mathrm{~L}^{-1}\right), \mathrm{FeSO}_{4} \cdot 7 \mathrm{H}_{2} \mathrm{O}\left(0.01 \mathrm{~g} \mathrm{~L}^{-1}\right)$, $\mathrm{K}_{2} \mathrm{SO}_{4}\left(0.35 \mathrm{~g} \mathrm{~L}^{-1}\right)$ and $\mathrm{MgSO}_{4} \cdot 7 \mathrm{H}_{2} \mathrm{O}\left(0.5 \mathrm{gL}^{-1}\right)$ with an initial $\mathrm{pH}$ of 6.5 . The inoculum was prepared by transferring $10 \mathrm{~mL}$ of pre-inoculum into the inoculation medium and subsequently it was grown for 3 days at $28^{\circ} \mathrm{C}$ and $140 \mathrm{rpm}$. The inoculum $(3 \%, v / v)$ was transferred to the fermentation medium containing sucrose $\left(200 \mathrm{~g} \mathrm{~L}^{-1}\right), \mathrm{NaNO}_{3}\left(20 \mathrm{~g} \mathrm{~L}^{-1}\right), \mathrm{FeSO}_{4} \cdot 7 \mathrm{H}_{2} \mathrm{O}\left(0.01 \mathrm{~g} \mathrm{~L}^{-1}\right)$, $\mathrm{K}_{2} \mathrm{SO}_{4}\left(0.35 \mathrm{~g} \mathrm{~L}^{-1}\right)$ and $\mathrm{MgSO}_{4} \cdot 7 \mathrm{H}_{2} \mathrm{O}\left(0.5 \mathrm{~g} \mathrm{~L}^{-1}\right)$. In the experimental design assays, optimization of the fermentation conditions was performed by varying the temperature and the agitation speed.

\subsection{Experimental design and data analysis}

The optimal temperature and agitation speed levels for maximizing the total FOS production were studied using a $2^{k}$ full-factorial design with 2 factors and 3 central points, according to Table 1 . Based on preliminary experiments (data not shown) and studies reported by other authors, $\mathrm{pH}$ was found to have no

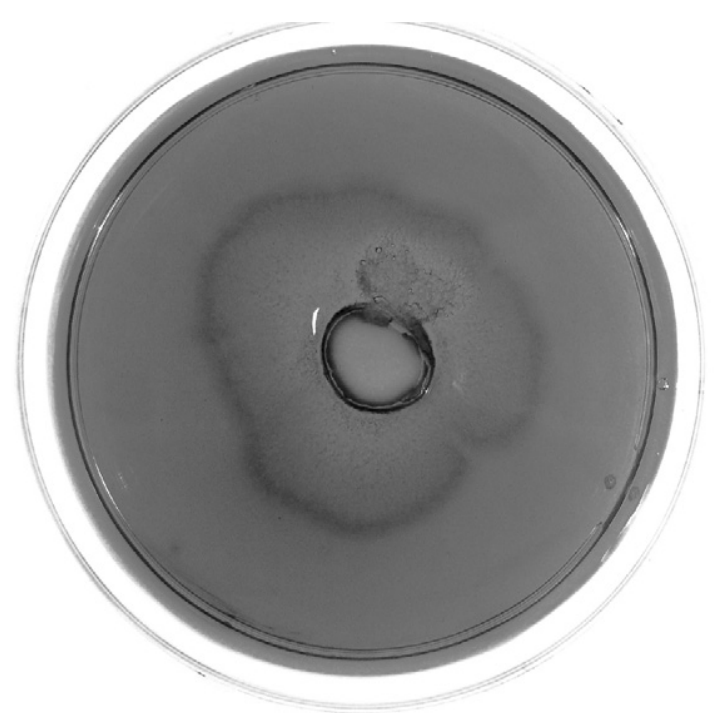

Fig. 1. Aureobasidium pullulans grown in Czapek Dox Media agar plates.

Table 1

Experimental range and levels of the factors tested in the $2^{2}$ full factorial central composite design.

\begin{tabular}{lllrrr}
\hline \multirow{2}{*}{ Factor } & \multicolumn{5}{l}{ Range and levels of factors } \\
\cline { 2 - 6 } & $-2^{1 / 2}$ & \multicolumn{1}{l}{-1} & \multicolumn{1}{c}{0} & +1 & $+2^{1 / 2}$ \\
\hline$X_{1}-$ Temperature $\left({ }^{\circ} \mathrm{C}\right)$ & 21 & 25.0 & 35 & 45 & 49 \\
$X_{2}-$ Agitation speed $(\mathrm{rpm})$ & 110 & 150 & 250 & 350 & 390 \\
\hline
\end{tabular}

significant effect on total FOS production yield so it was not considered as an optimization parameter (Madlová, Antosová, Baráthová, Polakovic, Stefuca, \& Báles, 1999).

An additional central composite design was used to optimize those experimental conditions by means of a response surface methodology. Therefore, 4 extra experiments were carried out to rotate the central composite design, setting the distance from the central design equal to the square root of 2 . The parameters ranges were chosen according to previous data on the optimum conditions for biomass growth, enzyme production and activity for this microorganism (Shin et al., 2004; Vandáková, Platková, Antošová, Báleš, \& Polakovič, 2004; Yun, Kim, \& Song, 1997). The two independent factors (temperature and agitation speed) were studied at 5 levels $\left(-2^{1 / 2},-1,0,+1\right.$ and $\left.+2^{1 / 2}\right)$ and a set of 11 experiments was carried out randomly according to the combinations presented in Table 2 .

\section{Table 2}

Experimental design and results of the $2^{2}$ full factorial central composite design used for the optimization of the total FOS production.

\begin{tabular}{rrlll}
\hline \multirow{2}{*}{ Run } & $x_{1}$ & $x_{2}$ & \multicolumn{2}{l}{$\%$ FOS $(\mathrm{w} / \mathrm{w})$} \\
\cline { 3 - 4 } & & & Observed & Predicted \\
\hline 1 & 0 & 0 & 61.9 & 61.4 \\
2 & 0 & 0 & 63.7 & 61.4 \\
3 & +1 & -1 & 52.9 & 50.0 \\
4 & -1 & +1 & 60.9 & 61.3 \\
5 & -1 & -1 & 56.1 & 56.4 \\
6 & 0 & 0 & 58.7 & 61.4 \\
7 & +1 & +1 & 58.1 & 54.9 \\
8 & $-2^{1 / 2}$ & 0 & 55.9 & 54.9 \\
9 & $+2^{1 / 2}$ & 0 & 42.1 & 57.8 \\
10 & 0 & $-2^{1 / 2}$ & 56.3 & 64.4 \\
11 & 0 & $+2^{1 / 2}$ & 62.9 & \\
\hline
\end{tabular}


For the statistical treatment, the factors were coded according to the following equation:

$x_{i}=\frac{X_{i}-X_{0}}{\Delta X_{i}}, \quad i=1,2$

where $x_{i}$ is the coded value of the independent factor, $X_{i}$ is the real value of the independent factor, $X_{0}$ is the real value of the independent factor at the central point and $\Delta X_{i}$ is the step change value.

It is expected that the behaviour of the system could be explained by a second-order equation, used for predicting the optimal total FOS yield point $(y)$, based on the coded values of the independent factors $\left(x_{i}\right)$ :

$y=\beta_{0}+\beta_{1} x_{1}+\beta_{2} x_{2}+\beta_{11} x_{1}^{2}+\beta_{22} x_{2}^{2}+\beta_{12} x_{1} x_{2}+\varepsilon$

where $y$ is the predicted response; the $\beta$ 's are parameters whose values are to be determined using multiple linear regression model (MRLM), being $\beta_{0}$ the intercept, $\beta_{1}$ and $\beta_{2}$ the linear coefficients, $\beta_{11}$ and $\beta_{22}$ the quadratic coefficients and $\beta_{12}$ the interaction coefficient; $x_{1}$ and $x_{2}$ are the coded independent factors and $\varepsilon$ is a random error term of the regression model, which should be independent and follow a normal distribution, in accordance to the requirements of the MRLM.

Design-Expert 6.0.6. (Trial version) and Statistical Package for Social Sciences (SPSS, version 14) were used for the experimental design and regression analysis of the experimental data. The significance of the regression model was evaluated using analysis of variance (ANOVA). The quality of the fit obtained using the regression model equation was statistically checked by the magnitude of two diagnostic residuals: the multiple or adjusted coefficient of determination ( $R^{2}$ or $R^{2}$ adj, respectively) and the predicted coefficient of determination $\left(Q^{2}\right)$. The $R^{2}$-values describe the goodness of fit, giving an idea of how well current runs can be reproduced by the mathematical model. The $Q^{2}$-value describes the goodness of prediction, showing how well new experiments can be predicted using the mathematical model. $R^{2}$ and $Q^{2}$ values higher than 0.75 and 0.60 indicate that the model is good, and $Q^{2}$ values lower than 0.25 indicate that the model is useless (Mandenius \& Brundin, 2008).

The discrimination ability of the model was also inferred by calculating the adequate precision value, which compares the range of the predicted values at the design points to the average prediction error. A value greater than 4 indicates an adequate model discrimination. The significance of the regression coefficients was tested using a $t$-test. Simultaneously, the independence and the normal distribution of the regression model errors were studied using the Durbin-Watson and the Shapiro-Wilk's tests, respectively. For the former, a statistic value of $2.0 \pm 0.2$ will guarantee the independence of the error term. Also, the required non multi-collinearity condition between the independent variables was evaluated using the variance inflation factor (VIF) and the condition index statistics. The independent variables will be non-collinear if values lower than 10 and 30, respectively, are obtained. Moreover, the presence of outliers was also checked by means of the outlier $t$-test, which tests if a run (experiment result) is consistent with the other runs, assuming that the model developed is suitable. Values higher than 3.5 indicate the presence of an outlier. Finally, the contour plots obtained from the second-order model proposed were also used to infer about the optimal experimental conditions keeping the independent factors within the experimental range studied. To validate the optimal operation condition levels that maximize total FOS production given by the model, 3 additional experiments were carried out.

\subsection{Sugars analysis}

Sugar concentrations in the fermentation broth were analyzed by high-performance liquid chromatography (HPLC). A modular liquid chromatograph (Jasco) equipped with a Prevail Carbohydrate ES column $(5 \mu \mathrm{m}, 250 \times 4.6 \mathrm{~mm})$ from Alltech was used, at room temperature. Elution was achieved using a mixture of acetonitrile and $0.04 \%$ ammonium hydroxide in water $(70: 30, \mathrm{v} / \mathrm{v})$ at a flow rate of $1.0 \mathrm{~mL} \mathrm{~min}^{-1}$. The response of the refractive index detector was recorded and integrated using the Star Chromatography Workstation software (Varian) (Dias et al., 2009).

\subsection{Cell growth}

Cellular growth was quantified by biomass determination (dry weight) using a microwave oven. Briefly, $10 \mathrm{~mL}$ of the fermentation broth was filtered through a $0.45 \mu \mathrm{m}$ filter and dried in a microwave oven for $15 \mathrm{~min}$ at $150 \mathrm{~W}$. The filter was then placed in a desiccator to cool for $10-15 \mathrm{~min}$ and afterwards it was weighted. Also, all filters were dried and weighted before the filtration (Olsson \& Nielsen, 1997). This procedure was done in triplicate for each fermentation broth sample.

\section{Results}

\subsection{Effects of the fermentation conditions on FOS production}

The factorial design enabled the identification of the fermentation conditions that play a significant role on the total FOS production. The factorial design, experimental data and predicted results are given in Table 2.

MLRM was performed to fit the response function (y corresponds to the \% total FOS in $\mathrm{w} / \mathrm{w}$ ) with the experimental data, allowing to obtain a significant second-order polynomial model. This model was established taken into account that the global model, as well as their coefficients must be statistically significant at the usual significance levels (5\% or $10 \%$ ), however keeping in mind that (Mandenius \& Brundin, 2008; Montgomery, 1997):

(i) Effects are disregarded from the analysis if the hierarchy of the model is not affected.

(ii) Effects are not removed if the final model is a ridge system where several local optimum points exist and the real stationary point is not inside the region of exploration for fitting the second-order model.

(iii) To ensure that the final model has a satisfactory prediction performance the predicted coefficient of determination value must be greater than 0.25 .

Bearing in mind the above-mentioned considerations, a MLRM was established to fit the response function based only on the linear and quadratic parameters, allowing deriving a reduced secondorder model. The statistical significance of the model and the coefficients of the response surface were evaluated using the $F$ test analysis of variance (ANOVA) and student $t$-test, respectively (Tables 3 and 4):

$y=61.433-3.190 x_{1}+2.417 x_{2}-5.543 x_{1}^{2}-0.241 x_{2}^{2}$

The model was found to be statistically significant $(P=0.0095)$ and did not show lack-of-fit $(P=0.4447)$. Moreover, it showed an acceptable determination coefficient $\left(R^{2}=0.862\right)$ that explains $86.2 \%$ of the response variability, as well as a satisfactory adjusted determination coefficient $\left(R^{2}\right.$ adjusted $\left.=0.769\right)$. Also, a satisfactory prediction determination coefficient was obtained $\left(Q^{2}=0.442\right)$ showing that the prediction performance of the proposed model is 
Table 3

Analysis of variance (ANOVA) for the second-order model determined for \% total $\operatorname{FOS}(\mathrm{w} / \mathrm{w})$.

\begin{tabular}{lrrrll}
\hline Source & \multicolumn{1}{c}{ SS } & DF & \multicolumn{1}{l}{ MS } & $F$-value & $P$-value \\
\hline Model & 313.44 & 4 & 78.36 & 9.34 & 0.0095 \\
Residual & 50.30 & 6 & 8.39 & & \\
Lack of fit & 37.51 & 3 & 9.38 & 1.46 & 0.4447 \\
Pure error & 12.83 & 2 & 6.41 & & \\
Total & 363.78 & 10 & & & \\
\hline
\end{tabular}

Table 4

Regression analysis using the $2^{2}$ full factorial central composite design.

\begin{tabular}{lllcc}
\hline Factor & $\beta$ 's coefficients & Standard errors & $t$-Values & $P$-values \\
\hline Intercept & 61.433 & \pm 1.673 & 36.727 & $<0.001^{*}$ \\
$x_{1}$ & -3.190 & \pm 1.024 & -3.114 & $0.021^{*}$ \\
$x_{2}$ & 2.417 & \pm 1.024 & 2.359 & $0.056^{* *}$ \\
$x_{1}^{2}$ & -5.543 & \pm 1.219 & -4.545 & $0.004^{*}$ \\
$x_{2}^{2}$ & -0.241 & \pm 1.219 & -0.198 & 0.850 \\
\hline
\end{tabular}

Statistically significant at a $5 \%$ significance level.

** Statistically significant at a $10 \%$ significance level.

acceptable. Furthermore, a small variation coefficient was obtained (equal to 5.54\%) and the model showed an adequate precision (equal to 9.49), which means that the proposed model can be used to navigate the design space and for optimization purposes. Finally, as required by the MRLM, the random error term $(\varepsilon)$ of the regression model was found to be independent $\left(d_{D W}=1.868\right)$ and to follow a normal distribution ( $P=0.861$, for the Shapiro-Wilk's test). In addition, no outliers were identified in the experimental data set, being, in general, the values of the outlier- $t$ test lower than 3.5. Also, no statistical evidences of multi-collinearity were found since the VIF and condition indexes calculated for all the terms included in the model (linear and quadratic terms) varied from 1.000 to 1.095 and were lower than 3.6 , respectively.

The three-dimensional response surface described by the model (Eq. (3)), for the region experimentally studied, is represented in Fig. 2. A comparison between experimental yield data and the model predicted values is shown in Fig. 3. As can be seen, the yield values estimated by the model are in good agreement with the experimental ones.

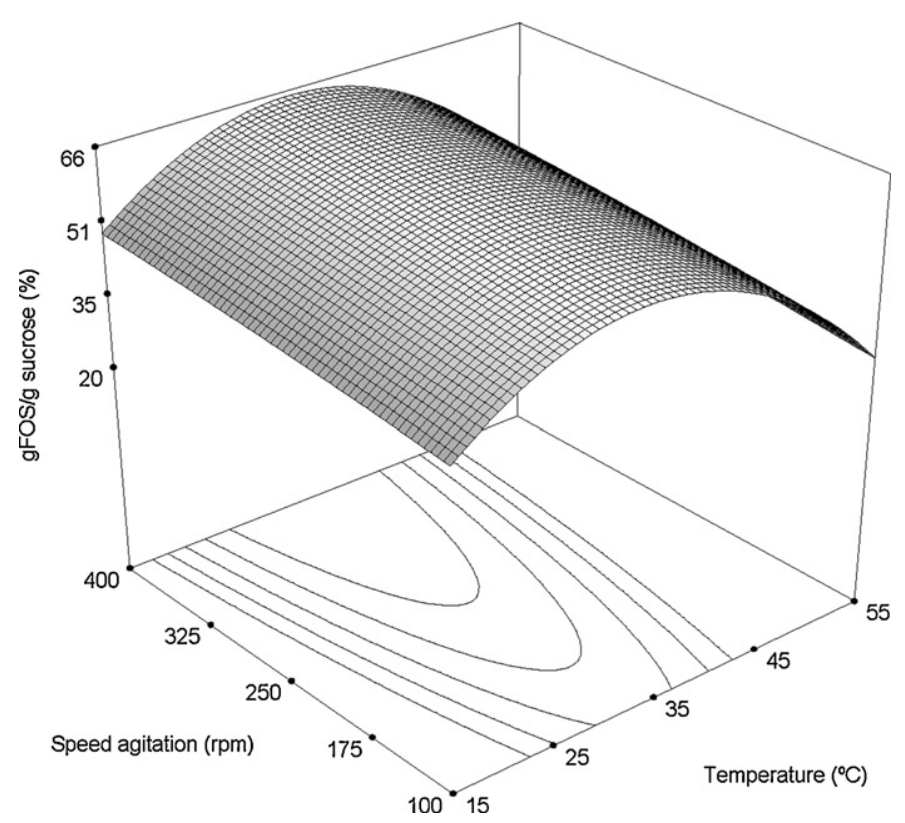

Fig. 2. Response surface described by the model in the experimental region studied.

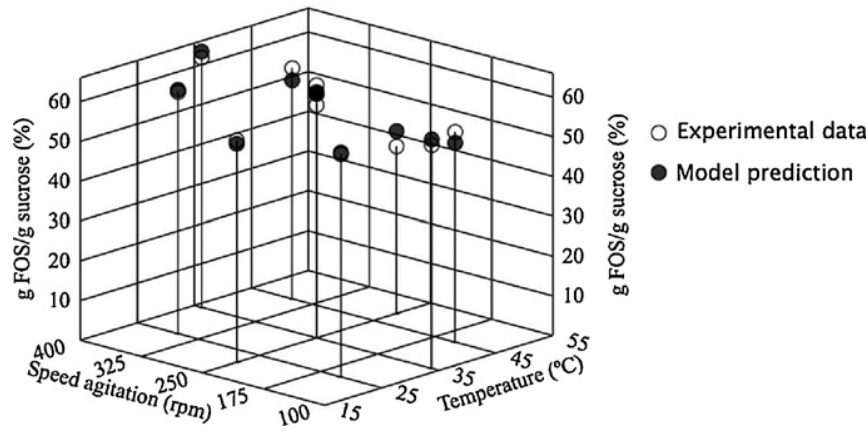

Fig. 3. Comparison between experimental results and the values predicted by the model.

Moreover, the fitted surface (Fig. 2) shows a possible maximum point based on the contour plots analysis, at a temperature of $32{ }^{\circ} \mathrm{C}$ and a speed of agitation of $385 \mathrm{rpm}$. Under these conditions, the corresponding maximum yield of total FOS predicted by the model was $64.7 \pm 8.8 \mathrm{~g}_{\text {Fos }} / \mathrm{g}_{\text {sucrose }}$ (95\% confidence). To validate these results, 3 independent fermentations were conducted at the optimized conditions (Fig. 4). On these experiments, an average total FOS yield of $64.1 \pm 0.0 \mathrm{~g}_{\text {FOS }} / \mathrm{g}_{\text {sucrose }}$ (1-kestose; $43.6 \mathrm{~g}_{1 \text {-kestose }} / \mathrm{g}_{\text {sucrose }}$; nystose; 20.6 gnystose $/ \mathrm{g}_{\text {sucrose }}$ ) was obtained, which is similar to the predicted value. The HPLC chromatogram of the fermentation broth at the maximum yield of FOS production (Fig. 5) demonstrates the clear FOS (in this fermentation point: 1-kestose and nystose) and sucrose separation. Using adequate calibration curves for each sugar it was possible to quantify their amount in each sample during the course of the fermentation.

\section{Discussion}

The base concepts in nutrition science have been changing in the last years and there has been an increasing interest in the use of oligosaccharides in diets, such as FOS (Roberfroid, 2007). A. pullulans is a FOS producing microorganism, and many studies have reported high total FOS production yields using the enzyme $\beta$-fructofuranosidase produced by this fungus (Lateef, Oloke, \& Prapulla, 2007; Sangeetha et al., 2004; Shin et al., 2004; Vandáková et al., 2004; Yoshikawa, Amachi, Shinoyama, \& Fujii, 2008). Usually, FOS production is a two-stage process, in which the first stage consists in the $\beta$-fructofuranosidase production by fermentation, and the second stage in the reaction of the enzyme with sucrose to

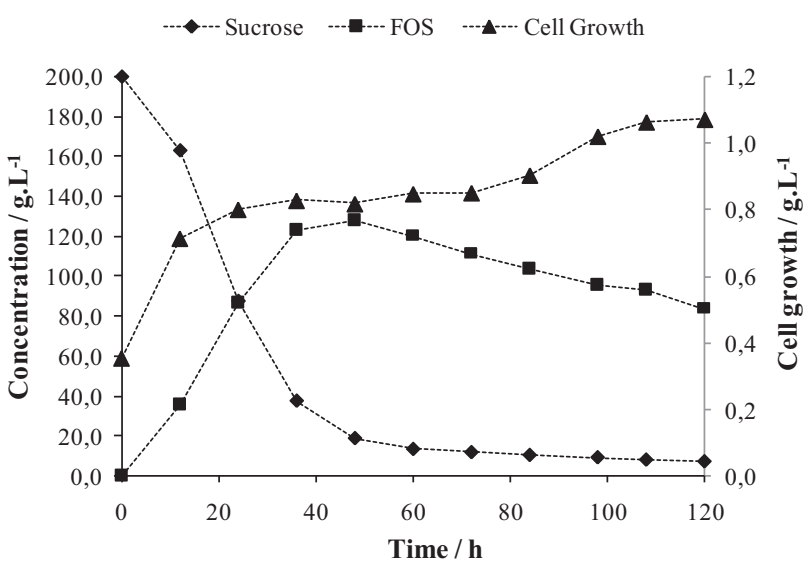

Fig. 4. Kinetics of cell growth (cell growth/g L ${ }^{-1}$ ), total FOS production and sucrose consumption (concentration $/ \mathrm{g} \mathrm{L}^{-1}$ ) for Aureobasidium pullulans using the optimized conditions. 


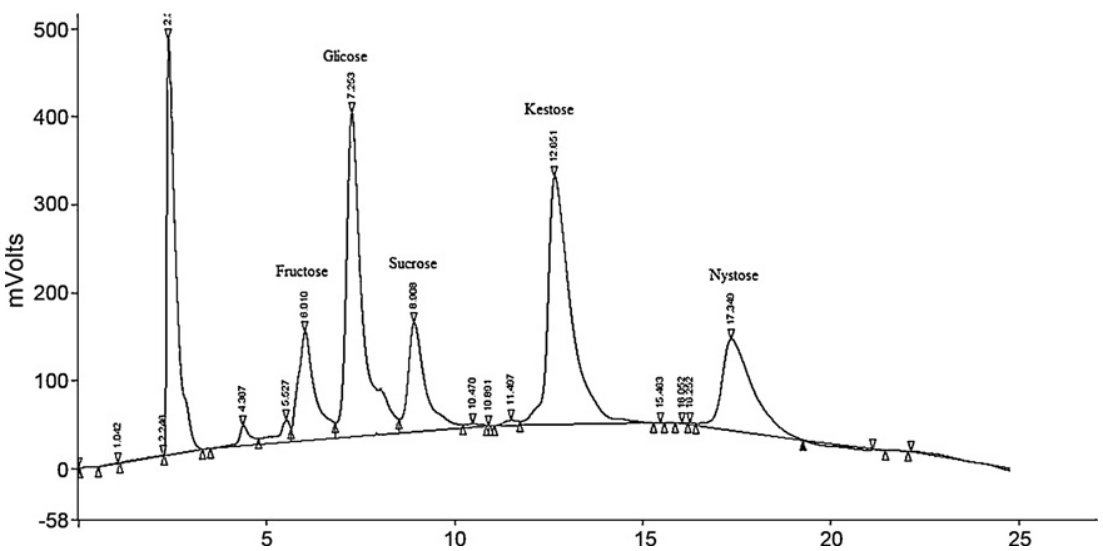

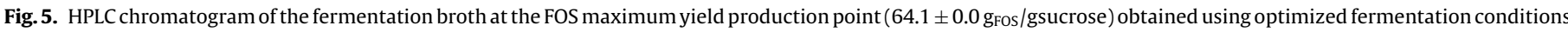
(temperature $=32^{\circ} \mathrm{C}$ speed of agitation $=385 \mathrm{rpm}$ ).

produce FOS (Sangeetha et al., 2004, 2005b; Yun, 1996; Yun et al., 1997).

The current study focused on the maximization of total FOS production in a one-stage process by $A$. pullulans using response surface methodology to optimize the operation parameters, namely temperature and agitation speed. Statistical tools have been commonly used to optimize fermentation parameters and consequently to maximize the production yields of a number of biotechnological compounds with commercial value as is the case of prebiotics (Aachary \& Prapulla, 2011; Prata et al., 2010; Torres et al., 2010; Vandáková et al., 2004).

The total FOS production yield obtained in the optimum operation conditions was found to be in accordance with the expected value predicted by the model, showing that the model was well fitted to the experimental data and thus describing accurately the studied region.

Yoshikawa and collaborators (2008) reported a $62.0 \%(\mathrm{w} / \mathrm{w})$ total FOS production yield produced from sucrose using crude enzyme preparations of $\beta$-fructofuranosidase obtained from sucrose-cultured cells of $A$. pullulans. Furthermore, Sangeetha et al. (2004) reported a $56.6 \%(\mathrm{w} / \mathrm{w})$ FOS maximum yield using fructosyl transferase from a culture broth homogenate of $A$. pullulans. In this same study, when cells of $A$. pullulans were used as source of fructosyl transferase, the maximum FOS production yield obtained was $55.9 \%(\mathrm{w} / \mathrm{w})$. The same authors in a further work (Sangeetha et al., 2005b) reported the use of a two-stage continuous process for maximizing FOS production by Aspergillus oryzae. In their study, the authors used response surface methodology tools for optimization purposes, and obtained a maximum FOS production yield of $58 \%$ (w/w). According to Lateef et al. (2007), the intracellular fructosyltransferase of a novel strain of $A$. pullulans was capable of producing $59 \%(\mathrm{w} / \mathrm{w})$ of total FOS within $9 \mathrm{~h}$ reaction time.

Therefore, comparing total FOS production yield $\left(64.1 \pm 0.0 \mathrm{~g}_{\text {FOS }} / \mathrm{g}_{\text {sucrose }}\right)$ obtained in the current work using a one-stage process with values reported by other authors using a two-stage process, it is interesting to notice that greater production yields were obtained, with the main advantage of reducing operational costs and time.

\section{Conclusions}

In summary, using response surface methodology it was possible to establish the fermentation conditions that maximize the total FOS production by $A$. pullulans $\left(32^{\circ} \mathrm{C}, 385 \mathrm{rpm}\right)$. A $64.1( \pm 0.0) \mathrm{g}_{\mathrm{FOS}} /$ $\mathrm{g}_{\text {sucrose }}$ total FOS production yield was obtained within $48 \mathrm{~h}$ of fermentation. Furthermore, it is important to notice that this production yield was obtained in a one-stage process, thus conferring this study an important role in the development of more efficient less expensive processes for the industrial production of FOS.

\section{Acknowledgments}

Agência de Inovação (AdI) - Project BIOLIFE reference PRIME 03/347. The authors Ana Dominguez, Clarisse Nobre and Duarte Torres acknowledge to Fundação para a Ciência e a Tecnologia, Portugal, for their PhD grants references SFRH/BD/23083/2005, SFRH/BD/32514/2006 and SFRH/BDE/15510/2004, respectively.

\section{References}

Aachary, A. A., \& Prapulla, S. G. (2011). Xylooligosaccharides (XOS) as an emerging prebiotic: Microbial synthesis, utilization, structural characterization, bioactive properties, and applications. Comprehensive Reviews in Food Science and Food Safety, 10(1), 2-16.

Biedrzycka, E., \& Bielecka, M. (2004). Prebiotic effectiveness of fructans of different degrees of polymerization. Trends in Food Science $\mathcal{E}$ Technology, 15(3-4), $170-175$

Bornet, F. R. J., Brounsl, F., Tashiro, Y., \& Duvillier, V. (2002). Nutritional aspects of short-chain fructooligosaccharides: Natural occurrence, chemistry, physiology and health implications. Digestive and Liver Disease, 34(Sup 2), S111-S120.

Chien, C. S., Lee, W. C., \& Lin, T. J. (2001). Immobilization of Aspergillus japonicus by entrapping cells in gluten for production of fructooligosaccharides. Enzyme and Microbial Technology, 29(4-5), 252-257.

De Preter, V., Hamer, H. M., Windey, K., \& Verbeke, K. (2011). The impact of preand/or probiotics on human colonic metabolism: Does it affect human health? Molecular Nutrition \& Food Research, 55(1), 46-57.

Dias, L. G., Veloso, A. C. A., Correia, D. M., Rocha, O., Torres, D., Rocha, I., et al. (2009). UV spectrophotometry method for the monitoring of galacto-oligosaccharides production. Food Chemistry, 113(1), 246-252.

Dominguez, A., Santos, I. M., Teixeira, J. A., \& Lima, N. (2006). New and simple plate test for screening relative transfructosylation activity of fungi. Revista Iberoamericana de Micología, 23, 189-191.

Gibson, G. R., Probert, H. M., Van Loo, J., Rastall, R. A., \& Roberfroid, M. B. (2004) Dietary modulation of the human colonic microbiota: updating the concept of prebiotics. Nutrition Research Reviews, 17, 259-275.

Lateef, A., Oloke, J. K., \& Prapulla, S. G. (2007). Purification and partial characterization of intracellular fructosyltransferase from a novel strain of Aureobasidium pullulans. Turkish Journal of Biology, 31, 147-154.

Lundstedt, T., Seifert, E., Abramo, L., Thelin, B., Nyström, Å., Pettersena, J., et al. (1998). Experimental design and optimization. Chemometrics and Intelligent Laboratory Systems, 42(1-2), 3-40.

Madlová, A., Antosová, M., Baráthová, M., Polakovic, M., Stefuca, V., \& Báles, V. (1999). Screening of microorganisms for transfructosylating activity and optimization of biotransformation of sucrose to fructooligosaccharides. Chemical Papers, 53(6), 366-369.

Mandenius, C. F., \& Brundin, A. (2008). Bioprocess optimization using design-of experiments methodology. Biotechnology Progress, 24(6), 1191-1203.

Montgomery, D. C. (1997). Response surface methods and other approaches to process optimization. In Montgomery D.C. Design and Analysis of Experiments. New York: John Wiley \& Sons., pp. 427-510.

Mussatto, S., Aguilar, C. Rodrigues, L. R, \& Teixeira, J. A. (2009a). Fructooligosaccharides and $\beta$-fructofuranosidase production by Aspergillus japonicus immobilized on lignocellulosic materials. Journal of Molecular Catalysis B: Enzymatic, 59(1-3), 76-81. 
Mussatto, S., Aguilar, C., Rodrigues, L. R., \& Teixeira, J. A. (2009b). Colonization of Aspergillus japonicus on synthetic materials and application to the production of fructooligosaccharides. Carbohydrate Research, 344(6), 795-800.

Olsson, L., \& Nielsen, J. (1997). On-line and in situ monitoring of biomass in submerged cultivations. Tibtech, 15(12), 517-522.

Playne, M. J., \& Crittenden, R. G. (2004). Prebiotics from lactose, sucrose, starch, and plant polysaccharides. In J. R. Neeser, \& J. B. German (Eds.), Bioprocesses and Biotechnology for Functional Foods and Nutraceuticals (pp. 99-135). New York: Marcel Dekker Inc.

Prata, M. B., Mussatto, S. I., Rodrigues, L. R., \& Teixeira, J. A. (2010). Fructooligosaccharide production by Penicillium expansum. Biotechnology Letters, 32(6), 837-840.

Qiang, X., YongLie, C., \& QianBing, W. (2009). Health benefit application of functional oligosaccharides. Carbohydrate Polymers, 77(3), 435-441.

Sangeetha, P. T., Ramesh, M. N., \& Prapulla, S. G. (2004). Production of fructooligosaccharides by fructosyl transferase from Aspergillus oryzae CFR 202 and Aureobasidium pullulans CFR 77. Process Biochemistry, 39(6), 753-758.

Sangeetha, P. T., Ramesh, M. N., \& Prapulla, S. G. (2005a). Recent trends in the microbial production, analysis and application of fructooligosaccharides. Trends in Food Science \& Technology, 16(10), 442-457.

Sangeetha, P. T., Ramesh, M. N., \& Prapulla, S. G. (2005b). Maximization of fructooligosaccharide production by two stage continuous process and its scale up. Journal of Food Engineering, 68(1), 57-64.
Shin, H. T., Baig, S. Y., Lee, S. W., Suh, D. S., Kwon, S. T., Lim, Y. B., et al. (2004). Production of fructo-oligosaccharides from molasses by Aureobasidium pullulans cells. Bioresource Technology, 93(1), 59-62.

Tanriseven, A., \& Aslan, Y. (2005). Immobilization of Pectinex Ultra SP-L to produce fructooligosaccharides. Enzyme and Microbial Technology, 36, 550-554.

Torres, D. P. M., Gonçalves, M. P., Teixeira, J. A., \& Rodrigues, L. R. (2010). Galactooligosaccharides: Production, properties, applications and significance as prebiotics. Comprehensive Reviews in Food Science and Food Safety, 9(5), 438-454.

Vandáková, M., Platková, Z., Antošová, M., Báleš, V., \& Polakovič, M. (2004). Optimization of cultivation conditions for production of fructosyltransferase by Aureobasidium pullulans. Chemical Papers, 58(1), 15-22.

Yoshikawa, J., Amachi, S., Shinoyama, H., \& Fujii, T. (2006). Multiple $\beta$ fructofuranosidases by Aureobasidium pullulans DSM2404 and their roles in fructooligosaccharide production. FEMS Microbiology Letters, 265(2), 159-163.

Yoshikawa, J., Amachi, S., Shinoyama, H., \& Fujii, T. (2008). Production of fructooligosaccharides by crude enzyme preparations of $\beta$-fructofuranosidase from Aureobasidium pullulans. Biotechnology Letters, 30(3), 535-539.

Yun, J. W. (1996). Fructooligosaccharides - occurrence, preparation, and application. Enzyme and Microbial Technology, 19(2), 107-117.

Yun, J. W, Kim, D. H., \& Song, S. K. (1997). Enhanced production of fructosyltransferase and glucosyltransferase by substrate-feeding cultures of Aureobasidium pullulans. Journal of Fermentation and Bioengineering, 84(3), 261-263. 